\title{
Scalable Nonlinear Iterative Methods for Partial Differential Equations
}

X-C. Cai

\section{October 29, 2000}

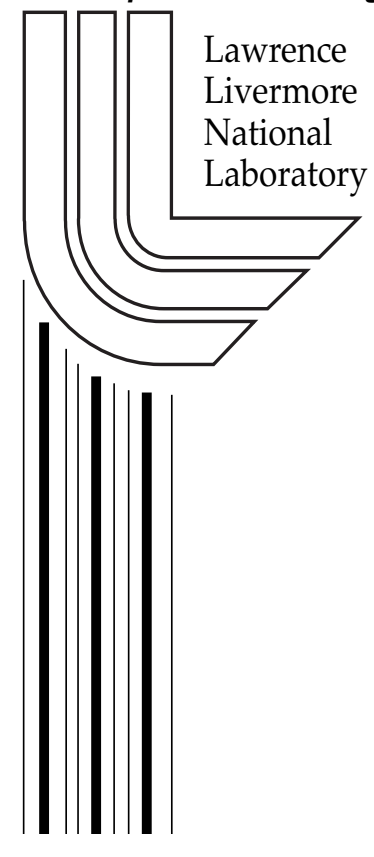




\section{DISCLAIMER}

This document was prepared as an account of work sponsored by an agency of the United States Government. Neither the United States Government nor the University of California nor any of their employees, makes any warranty, express or implied, or assumes any legal liability or responsibility for the accuracy, completeness, or usefulness of any information, apparatus, product, or process disclosed, or represents that its use would not infringe privately owned rights. Reference herein to any specific commercial product, process, or service by trade name, trademark, manufacturer, or otherwise, does not necessarily constitute or imply its endorsement, recommendation, or favoring by the United States Government or the University of California. The views and opinions of authors expressed herein do not necessarily state or reflect those of the United States Government or the University of California, and shall not be used for advertising or product endorsement purposes.

Work performed under the auspices of the U. S. Department of Energy by the University of California Lawrence Livermore National Laboratory under Contract W-7405-Eng-48. 


\section{Final Report}

Department of Computer Science

University of Colorado

Boulder, CO 80309-0430

\section{Scalable Nonlinear Iterative Methods \\ for Partial Differential Equations}

Submitted by:

Xiao-Chuan Cai

Associate Professor

\section{FINAL REPORT}

for the period ending July 10, 2000

Prepared for:

University of California

Lawrence Livermore National Laboratory

Attn: Jill Dunaway

P.O. Box 808, L-561

Livermore, CA 94551

October, 29, 2000 


\section{Final Report on LLNL Subcontract B509471: Scalable Nonlinear Iterative Methods for Partial Differential Equations}

\section{PI: Xiao-Chuan Cai}

\section{Project Overview}

We conducted a six-month investigation of the design, analysis, and software implementation of a class of singularity-insensitive, scalable, parallel nonlinear iterative methods for the numerical solution of nonlinear partial differential equations. The solutions of nonlinear PDEs are often nonsmooth and have local singularities, such as sharp fronts. Traditional nonlinear iterative methods, such as Newton-like methods, are capable of reducing the global smooth nonlinearities at a nearly quadratic convergence rate but may become very slow once the local singularities appear somewhere in the computational domain. Even with global strategies such as line search or trust region the methods often stagnate at local minima of $\|F\|$, especially for problems with unbalanced nonlinearities, because the methods do not have built-in machinery to deal with the unbalanced nonlinearities. To find the same solution $u^{*}$ of $F(u)=0$, we solve, instead, an equivalent nonlinearly preconditioned system $G\left(F\left(u^{*}\right)\right)=0$ whose nonlinearities are more balanced. In this project, we proposed and studied a nonlinear additive Schwarz based parallel nonlinear preconditioner and showed numerically that the new method converges well even for some difficult problems, such as high Reynolds number flows, when a traditional inexact Newton method fails.

\section{Papers Supported in Part by the Subcontract}

[1] Xiao-Chuan Cai and David E. Keyes, Nonlinearly Preconditioned Inexact Newton Algorithms, SIAM J. Sci. Comput, 2000, submitted.

[2] Xiao-Chuan Cai and David E. Keyes, A Nonlinear Additive Schwarz Preconditioned Newton's Method, Proceedings of the 13th International Conference on Domain Decomposition Methods. To be submitted.

\section{Concluding Remarks}

We developed a general framework of nonlinearly preconditioned inexact Newton methods. As an example, we formulated and tested numerically a nonlinear additive Schwarz preconditioner. Our test results for a two-dimensional incompressible flow problem showed that the method is fast, and insensitive to the high Reynolds numbers. The method has great potential for other nonlinearly difficult problems, such as (1) problems whose solutions have local singularities such as shocks or nonsmooth fronts; and (2) multi-physics problems with drastically different stiffness that require different nonlinear solvers based on a single physics submodel. 